\title{
Estudio de cilias respiratorias y requerimientos básicos de la muestra para microscopía electrónica de transmisión
}

\section{Basic requirements for samples of respiratory cilia for transmission electron microscopy}

LUZ FERnANDA SUA MD, PHD ${ }^{1}$

\section{Introducción}

La discinesia ciliar primaria (DCP) es una enfermedad hereditaria, principalmente autosómica recesiva, caracterizada por disfunción de las células ciliadas presentes en los tejidos respiratorio y gonadal, entre otros. La prevalencia aproximada de síndrome de Kartagener, que basa el diagnóstico en el estudio ultraestructural ciliar, es de 1/10 000 nacidos vivos $(1,2)$.

La DCP incluye un grupo de enfermedades en la que las cilias respiratorias son inmóviles (síndrome de inmovilidad ciliar), el movimiento ciliar es discinético e ineficaz (DCP) o no hay cilias (aplasia ciliar), este último es extremadamente infrecuente $(1,3,4)$. En 1976, Afzelius describió como origen del trastorno, la ausencia de brazos de dineína en los microtúbulos de las cilias bronquiales y de los flagelos de los espermatozoides (5).

La célula ciliada normal se compone por unas 250 proteínas organizadas en torno a un axonema o conjunto de microtúbulos, que se extiende desde el citoplasma hasta el extremo final de la cilia. La cilia normal consiste en un par central de microtúbulos rodeados por una vaina y otros 9 dobletes externos, formando la organización característica «9+2». Los complejos de dineína se asocian con los dobletes periféricos; los puentes de nexina sostienen los dobletes periféricos entre sí; y los rayos radiales (radial spoke) unen el par central con los periféricos.

Los microtúbulos y sus proteínas asociadas están anclados en el citoplasma apical de la célula por un complejo de 9 tripletes de microtúbulos. La función de las cilias respiratorias es realizar un batido coordinado con una frecuencia y patrón correcto para el aclaramiento de las secreciones y eliminación de los desechos de la vía aérea (Figura 1) (6-9).

Actualmente, el diagnóstico de DCP se basa en el estudio funcional y estructural de las cilias obtenidas de muestras de la mucosa respiratoria (nasal o bronquial).
${ }^{1}$ Especialista en Anatomía Patológica y Patología Clínica. Patología Pulmonar. Doctora en Ciencias Biomédicas con énfasis en Genómica de Tumores Sólidos. Departamento de Patología y Medicina de Laboratorio. Línea de investigación biomédica en tórax. Fundación Valle del Lili. Profesora Clínica Asistente de la Facultad de Ciencias de la Salud de la Universidad Icesi. Cali, Colombia. Autor de correspondencia Luz Fernanda Sua.

Correos: lufer24@hotmail.com, luz. sua@fvl.org.co

Recibido: 20/08/17. Aceptado: 01/11/17. 


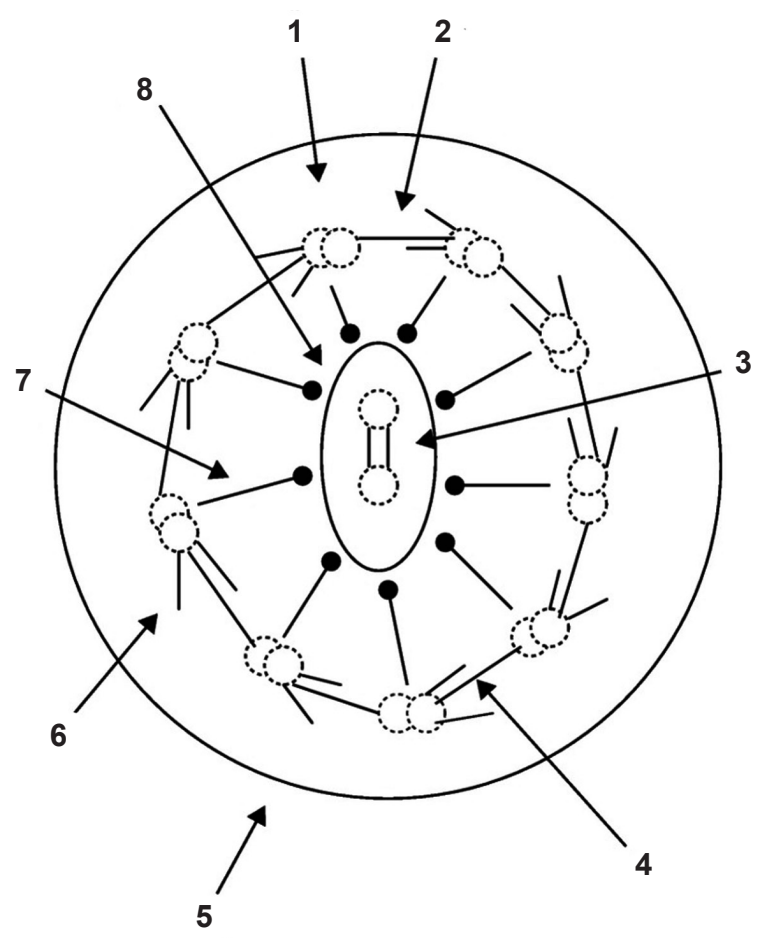

Figura 1. Ultraestructura del axonema. 1. Doblete de microtúbulos. 2. Uniones de nexina. 3. Puente de conexiones. 4. Brazo interno de dineína. 5. Membrana ciliar. 6. Brazo externo de dineína. 7. Radiaciones. 8. Microtúbulos centrales y membrana central.

\section{Requerimientos básicos de la muestra para un correcto diagnóstico de DCP}

\section{Espécimen}

Se requiere representación ciliar del epitelio, pues es en la cilia donde se realizan los estudios de ultraestructura y se determina el diagnóstico de DCP.

\section{Medio de fijación}

Una vez obtenida la muestra se debe fijar en glutaraldehído al 2,5\% para su preservación, este es un punto crucial de una buena interpretación. Más adelante en el proceso, la muestra se incluye en resina para los cortes finos, esto permite determinar la presencia de cilias y seleccionar las mejores muestras para el estudio de ultraestructura.

\section{Estudio de microscopia electrónica de transmisión}

Realizamos el estudio en busca de pérdida de brazos de dineína, interno y/o externo, desorganización de la distribución de los dobletes, pérdida de túbulos o de dobletes centrales (Figura 2 y $\mathbf{3}$ ).

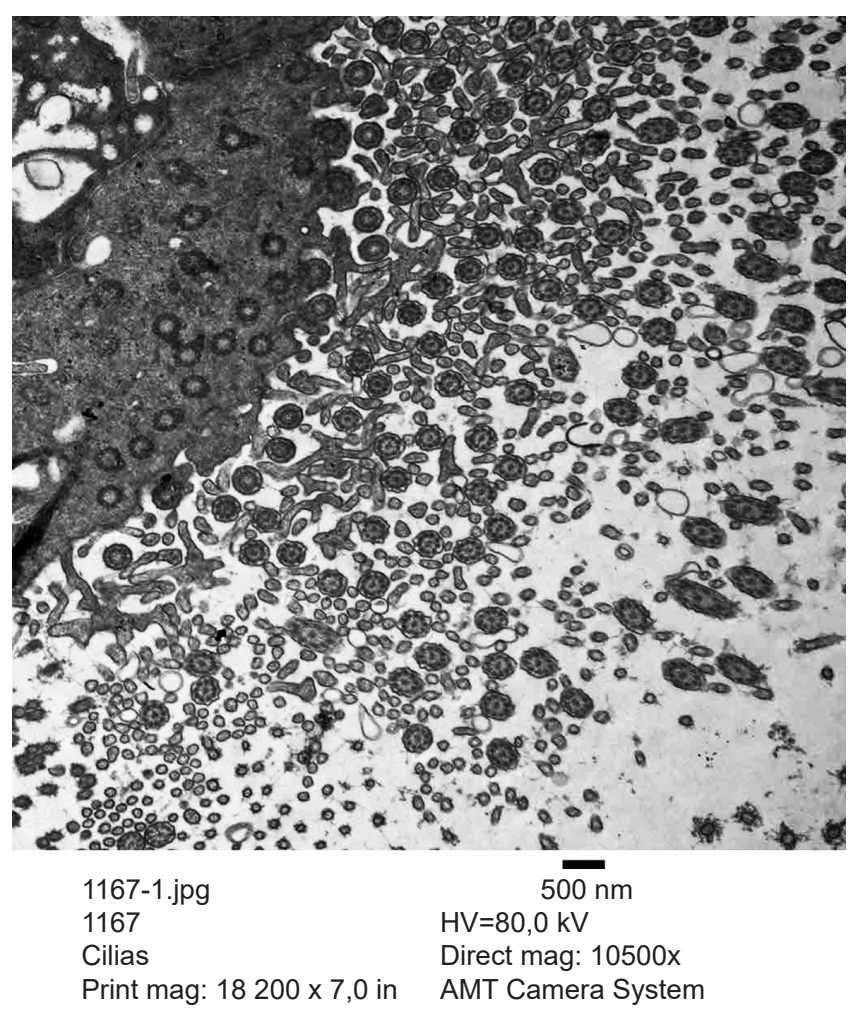

Figura 2. Representación del epitelio respiratorio con el número de cilias adecuadas para estudio ultraestructural. Imagen originada en el Laboratorio de Patología de la Fundación Valle del Lili.

\section{Conclusiones}

Actualmente, el diagnóstico de DCP se realiza con más frecuencia debido al mayor conocimiento de esta entidad y a la disponibilidad de los medios necesarios para el mismo en centros de referencia. La detección temprana de estos pacientes posibilitará la aplicación de una serie de recursos terapéuticos que mantengan una adecuada función pulmonar durante el mayor tiempo posible, con la consecuente disminución de la morbilidad y mejoría de la calidad de vida. 


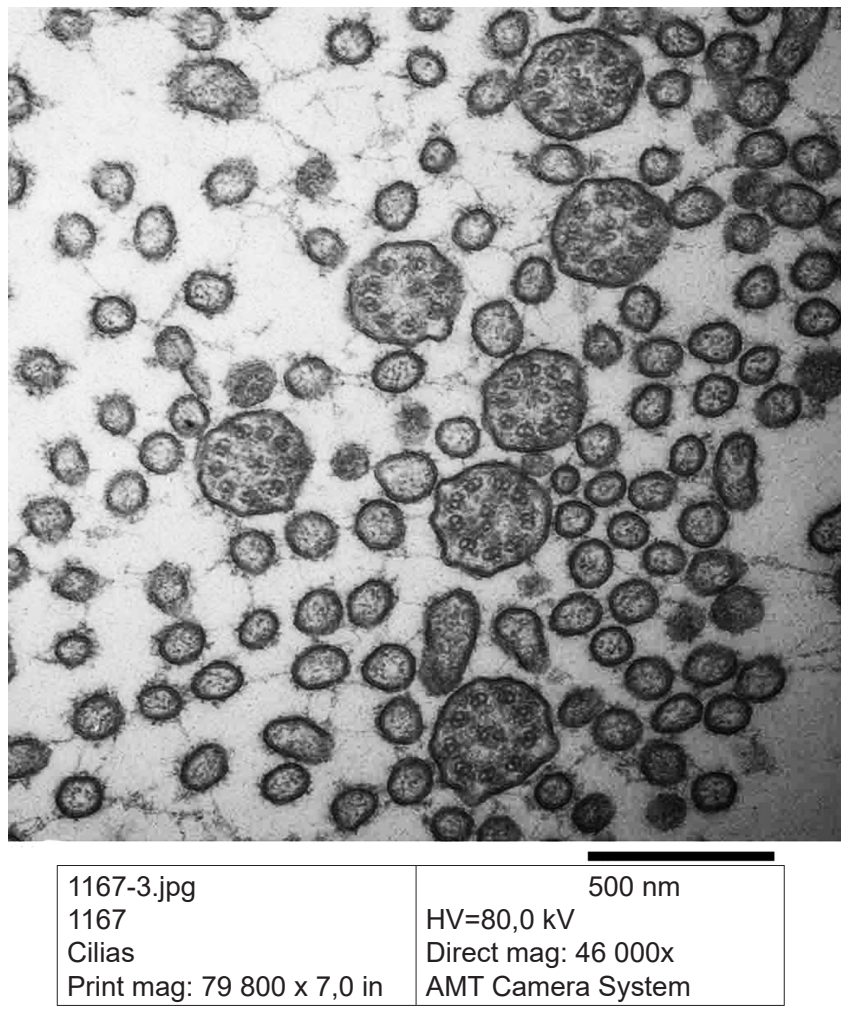

Figura 3. Estudio ultraestructural de cilias para el análisis de DCP. Imagen originada en el Laboratorio de Patología de la Fundación Valle del Lili.

\section{Conflicto de intereses}

La autora declara no tener conflictos de interés.

\section{Referencias}

1. Afzelius BA, Stenram U. Prevalence and genetics of immotile-cilia syndrome and left-handedness. Int $\mathrm{J}$ Dev Biol. 2006;50:571-3. DOI: http://dx.doi.org/10.1387/ ijdb.052132ba.

2. Bush A. Primary ciliary dyskinesia. Acta Otorhinolaryngol Belg. 2000;54(3):317-24.

3. Afzelius BA. Cilia related diseases. J Pathol. 2004;204:470477. DOI: http://dx.doi.org/10.1002/path.1652.

4. Bush A, Chodhari R, Collins N, Copeland F, Hall P, Harcourt $\mathrm{J}$, et al. Primary ciliary dyskinesia: current state of the art. Arch Dis Child. 2007;92(12):1136-40. DOI: http://dx.doi. org/10.1136/adc.2006.096958.

5. Afzelius BA. A human syndrome caused by immotile cilia. Science. 1976;193(4250):317-9. DOI: 10.1126/science. 1084576 .

6. Busquets R, Caballero-Rabascoa M, Velascoc M, Lloreta J, García-Algar D, Busquets RM. Discinesia ciliar primaria: criterios clínicos de indicación de estudio ultraestructural. Arch Bronconeumol. 2013;49(3):99-104. DOI: https://doi. org/10.1016/j.arbres.2012.10.007.

7. Busquets RM, García-Algar O. Discinesia ciliar primaria y secundaria. En: Cobos N, Pérez-Yarza EG (editores). Tratado de neumología infantil. 2a edición. Madrid: Ergon; 2009. p. 991-1005.

8. Ferkol T, Mitchison HM, O’Callaghan C, Leigh M, Carson $\mathrm{J}$, Lie $\mathrm{H}$, et al. Current issues in the basis mechanisms, pathophysiology, diagnosis and management of primary ciliary dyskinesia. Eur Respir Mon. 2006;37:291-313. DOI: 10.1183/1025448x.00037016.

9. Goodenough UW, Heuser JE. Substructure of inner dynein arms, radial spokes, and the central pair/projection complex of cilia and flagella. J Cell Biol. 1985;100(6):2008-18. DOI: 10.1083/jcb.100.6.2008. 